\title{
The Impact of Organizational Structure and Style of the Organization's Work on Organizational Conflicts (Field Study)
}

\author{
Hamdan Rasheed Abdullah Aljammal ${ }^{1}$ \\ ${ }^{1}$ Balqa Applied University, Jordan \\ Correspondence: Hamdan Rasheed Abdullah Aljammal, Balqa Applied University, Jordan. E-mail: \\ dr.hamdan_aljammal@yahoo.com \\ Received: June 11, 2015 \\ Accepted: August 20, 2015 \\ Online Published: August 22, 2015 \\ doi:10.5539/ijbm.v10n9p223 \\ URL: http://dx.doi.org/10.5539/ijbm.v10n9p223
}

This research has been published with the support of the Balqa Applied University, Jordan. This work has been carried out during sabbatical leave granted to the author Dr Hamdan Rasheed Abdullah Aljammal from Albalqa Applied university (BAU) during the academic year 2014.

\begin{abstract}
The study focuses on the organizational conflicts that occur within the organization and clarifies the concept of organizational conflicts and shows their causes. The study was applied at Irbid District Electricity Company in Jordan, where the researcher distributed the questionnaire on its employees, and then analyzed and drew conclusions and recommendations. The study came up with the following recommendations:

1) We should review and reconsider the organizational structure whenever it is needed to go with the developments in terms of the work expansion and the increased number of its institutions.

2) We should provide the employees with the all means and tools needed to accomplish their work on time specially that some units depend on each other to complete the work.

3) The study found that workers want to determine their tasks clearly and specifically.

4) The study found that some powerful staff, like those who have the authority in the organization in the organization, are hindering the work continuity in an unclear way to achieve their own purposes, and they give their personal benefits the priority on the account of the organization's benefit. This should be highly taken into consideration and banned.
\end{abstract}

Keywords: organizational structure, organizational conflicts, Jordan

\section{Introduction}

The conflict, disagreement and dispute between the individuals working at all levels of management institutions is a realistic phenomenon, which is impossible to be avoided because of the different personalities, reactive client, and the different nature of people and organizations at all levels. In supervisory and regulatory departments, and even in the board of directors in the organization. This considered one of the manifestations and the regulatory environment that cannot be ignored, and this conflict varies in the degree of severity and its impact on the organization and the individual by subject and the parties involved in it.

The organizational conflict is a natural phenomenon in the institutions and communities by the fact that communities have many differences in the social systems where each system founded has special concepts and methods of interaction, which are reflected in their effects on the individuals of this community and their attitudes, inclinations and aptitudes than creating some differences that come up to the point of conflict.

It is worth mentioning that the conflict may be within the same individual, and may be among the groups or individuals, and as an example is the individual's desire to get the money which creates inner conflict. This conflict increases because of anxiety and tension while selecting the alternatives between the good and evil, so Islam came to lead the humanity to the way of truth and make it avoid the evil way.

\subsection{The Importance of the Study}

The study is importance because of being an applied study providing real reasons for the conflict in general in different business organizations, and show the impact of the organizational structure of the organization on the 
conflict as well as the style of organization work of the Organization where the employees recognize all the levels of the organizational structure and business areas in all business organizations. This help them find out the reasons of conflicts, factors of continuity, and the role of the organization and its activities in increasing organizational conflicts which have the effect in increasing the performance of the employees in the organization and the effectiveness of the organization. The study comes to supplement the shortfall in the field of organizational conflicts, in terms of the causes and factors of continuity, and to enrich the subject of organizational conflict with knowledge and analysis as being a human phenomenon occurring in all organizations naturally.

\subsection{Goals of the Research}

The goal of this research to know the most important factors of creating the organizational conflict, and the reasons for to continue on the electric company of Irbid north Jordan and to know the effect on the organizational frame, and the methods of work of organizational on it, and the effect of it on the performance of the employees.

\subsection{Research Problem}

The corporations between employees consider the main frame of the success of an organization, and reaching its goals, The good organization frame will push away the conflicts factors, beside the method of the organization work will have the most effects on the organizational conflict, which will have the negative effects on the performance of the employees, and there corporation, and then the organization success, the researcher did notes, there are different types of conflicts between the employees of Irbid electric company.

Some of these conflicts are resulted from of the organizational frame, and other resulted from the ways and methods of works on the company .cursing the door to be open for conflicts to happen between employees and the groups of work team work inside the company. There for the conflicts are there creating worry and tension on the employees of the company.

Then we should determine the conflicts and determine the reasons that causes it, and try to eliminate what possible:

Upon that the problem of study will have the following inquires:

1) What is the effect of the organizational frame on the organizational conflicts on the company?

2) What is the effect of the mutual relationship at work on the organizational conflicts?

3) What is the effect of the ambiguity of goals and methods require contain over the organizational conflicts?

4) What is the effect of the conflicts roll over the organizational frame?

5) What is the effect of overlapping over the organizational frame?

\section{Previous Studies}

Juddah and Yafei study (2007) entitled "the relationship between leadership style, career commitment, and the ambiguity of role conflict, and some demographic variables in one of the public sector companies in the Arab Republic of Egypt.

The objective of this study is to investigate the relationship between the three variables, namely, (leadership style of the leader according to Fiedler theory, the organizational commitment, and role conflict and role ambiguity). The results showed a correlation between the style of the leader and his organizational commitment on one hand, and between the style of the leader and his sense of the role conflict and role ambiguity. It was also a negative relationship between organizational commitment of the leader and the ambiguous role conflict on the other. The study also found significant differences between the age, marital status, the career center, and the style of the leader on one hand, and between age, experience and educational attainment, sex, and the commander's feeling commander of the role conflict and ambiguity on the other hand. The data indicated that the largest percentage of the leaders involved in this research have adopted the style of the support.

Burgdh's study (2005) entitled "Organizational Conflict Management".

This study focused on the management of organizational conflicts in Algeria and the harmful and destructive effects of conflicts on the foundations, its members, and structures. He considered this phenomenon as the main reason of deficiency while practicing the regular activities causing difficulty for individuals and groups to coexist and work together peacefully at any institution and the study called for:

1) Choosing the style or strategy that is appropriate for the nature of each given problem to serve as the real 
reason for the conflict in the region.

2) A comprehensive analysis for all the attitudes and recognizing all aspects of the full strength and weaknesses of each strategy or style.

3) The effective management should settle all the organizational conflicts through research and audited studies, the and proper contacts so that it can intervene in the appropriate time.

4) Institutions need to have the necessary leadership skills and for managing and dealing with the organizational conflicts. This enables this institution to increase the performance and the effectiveness of the institution.

Abu Sheikha (2005) study entitled "the organizational climate and its relationship to personal and functional variables".

This study aimed at evaluating the prevailing organizational environment of the Jordanian employees in the public and private sectors according to eight dimensions (organizational structure, job descriptions, rewards system, teamwork, supervision system, managing differences and affiliations, and the physical conditions of work), which in turn form the general organizational environment.

The study showed that the assessment of staff for the organizational environment is negative in general. This imposes on the administration to pay attention to this issue in order to create a better environmental regulation which in turn leads to better performance. The most important outcomes of this study are:

1) Determining reference terms of the administrative units in order to achieve the organizational coordination and integration between these units.

2) Defining the powers and responsibilities of the occupants of these jobs accurately and clearly.

3) Enhancing the principle of delegation of authority delegation and this should be guaranteed by the prevailing regulations and instructions.

4) Applying a system for job descriptions that specifies the duties and responsibilities of specific functions. This systems should be appropriate for the expertise, capabilities and skills of the occupants.

5) Creating a reward system to stimulate the willingness of creativity and innovation among occupants.

6) Providing the opportunity for the employees to participate in setting goals, making decisions, and to keep the door open between the administration and workers.

7) Dealing with conflicts among the staff members by making round-table discussions to solves these problematic conflicts and issues.

8) Giving freedom to the subordinates to act as they recognize and understand the related issues, and encouraging them to give and share new ideas.

9) Determining the acceptable performance standards, and the presidents' expectations should be built after making constructive discussions with subordinates.

10) Including the appropriate qualified person in the job and place that he is best qualified to.

11) Involving employees in the decision-making process.

Othman's study (2002) entitled "the evaluation of the management techniques of organizational conflicts among managers of middle-administration companies for natural gas distribution, and trends of development".

The study aimed to identify the organizational conflicts and the kind of the opposing and divergent parties in the preliminary stages. It also aimed to identify the most important factors, and the reasons for organizational conflicts among individuals as well as the actual methods followed in this company to manage these conflicts. The most important findings of the researchers are the following:

There are conflicts inside individuals themselves due to the increased pressure imposed on them, and their inability to express themselves clearly. There are also conflicts among identical and non-identical individuals in the organizational structure. Another kind of conflict was also found among different groups and sections and among different organizations together. The researcher has attributed these emergent conflicts into different reasons, the most important of them are: the scarcity of resources, the complexity of the business, the lack of the role clarity, and the organization's policy represented by: the lack of employees' participation in the decision-making process, the administration's different treatment with its individuals, the method of disclosure and transparency, and the availability and diversity of communication, and management style of the granted financial rewards and incentives and the people who decides the amount and individuals deserving these rewards. 
The researcher has summarized that the methods of conflict management, which are supposed to be followed by natural gas company as the following: teamwork, increasing the resources which are disputed, developing the standards of fair and equal promotions and financial rewards and incentives, improving the channels of communication, disclosure, transparency and equality in the distribution of information, integrating the competing units, and decreasing reliability among individuals, and increasing training courses for the individuals.

Bin Saeed Al-Qahtani study (2001) entitled "Causes of Regularity Conflicts in the Central Governmental Agencies in Saudi Arabia".

This study analyzed the phenomenon of the organizational conflicts in the administrative bodies in Saudi Arabia, and the researcher has come up with the following results and recommendations:

1) Identifying the staffs' functions and specifying their functions, responsibilities, and their roles clearly to provide the necessary information for them to achieve justice, flexibility and the required balance between the granted powers granted and the work required from them to perform without ambiguity.

2) The development of team spirit at work to reduce the rush toward authority monopoly which is reflected positively on the staffs' relations and their view of their roles at work.

3) Creating the spirit of harmonization, belonging, and loyalty among different-level employees in terms of qualification, experience, and cognitive abilities in order to avoid conflicts.

4) Developing a special organizational culture that combines different values and norms prevailing in the society, so as it deals with the various tendencies, and values and norms. Also, studying the organizational conflict factors in all the administrative organs and test their relationship to personal factors.

5) Finding ways to achieve the employees' satisfaction to ensure the development of their performance, whether through incentives or achieving the career ambitions logically and reasonably.

6) Clarifying the harmful effects of the closed self behaviors that make confined to his personal benefits, and that create the sense of isolation and aggression toward others.

7) Providing the parts of the organization with sufficient and accurate information that meet the requirements of the work, and help the employee understand the work.

8) Re-evaluating the level of the workforce in each department to make sure the number of the employees fits the tasks and missions carried out.

10) The administration should take the initiative to identify the causes of organizational conflict erupted to control it.

Sheriff's study (1995) entitled "The impact of the role conflict and its ambiguity on the job satisfaction for the retail sellers in Omar Effendi Company".

The aim of this study was to determine the impact of role conflict and its ambiguity on job satisfaction. The study was applied on 338 individual selected through random sampling regulators of the total 1430 workers. Those workers are retail sellers in Omar Effendi Company, and their supervisors in the five branches of the company who were selected from the twenty-five branch in Cairo. The study came up with enhancing result that role ambiguity inversely associated with job satisfaction.

Nada's study (1991) entitled “The impact of the environmental, organizational and behavioral variables on the performance efficiency in hospitals; a comparative study between role conflicts, the conflict between the groups, and the conflict between the organizations." These variables are behavioral variables in the application part. The study came up with some results, the most important of them are: these conflicts result in a decrease in the performance level rates in comparison with the normal rates, and the dissatisfaction of the beneficiaries about the provided services. The researcher has also summarized the reasons behind the doctors' dissatisfaction in this hospital; the most important of them are: low incentives and rewards, bad relations with their superiors, the imbalance between the salary and the amount of performed work and tasks, the work, and discrimination the bosses' preferential treatment for some staff and workers over the others. As for the overall reasons for the whole employees' dissatisfaction are: the bad and unjust treatment of the administrative staff for the workers and work pressure. These two reasons are the major cause behind the organizational conflict. On the contrary, the researcher found that the spirit of cooperation among colleagues and intimate relations among them are the most important reasons for job satisfaction.

The conflict has been defined as a competitive situation in which the conflict parties are aware of the possible 
inconsistency in obtaining the future positions, and each part wants to get in the future positions and each part wants to get in the position which is undesirable for the other part. (Blind, 2005, p. 363).

\subsection{Theoretical Frame}

The term "conflict" indicates an existence of differences or contradiction among the goals of the organization employees. It also means that it has two or more different parties with no obvious opponent. Unlike competition, conflict parties may resort to violence to achieve their goals, so the term means a fierce dispute among the parties.

"Conflict "means disputes, differences, and disagreements that lead to violence. Linguistically, it means the contradiction between terms, emotions, and behaviors, which in turn leads to rupture. Conflict comes as a result of any change in the organization or society. Some people stick to the past to save their personal interests, and others look at the change as a means for modernization. Sometimes it is possible for the conflict to be positive and purposeful for the interest of the organization, where energies, talents, and efficiencies of individuals are spurted to meet their goals.

Conflict is defined as a collapse of the standard decision making mechanism that leads to difficulty in choosing between alternatives of mind or performance (Al-Taweel, 1986, p. 267). It also confuses the means of decision making which makes alternatives too difficult to be chosen (Alkahtani, 2001, p. 152). Some people define "conflict" as a contradiction between certain desires of the individual, or a tension between individuals or groups because of lack of harmony, or differences between goals, or between the means that lead to these goals and desires (Ahmad, 1994, p. 191).

The concept of "organizational conflict" is related to a conflict process that is founded as a reaction from an individual or a group or an organization to make pressure on another individual or group, either inside the work place or in another society, for the purpose of creating some positive or negative changes on the structure and criteria of that individual or group or organization. Barker (1988) indicates that the conflict happens in such organizational situations that need non-compatible activities, the activities in which a personal action of an individual may hurt or intervene or contradict others' activities. This of course will decree the output of these activities. Conflict is also defined as a kind of action from which a person starts feeling that others negatively affect his performance (Alqarioti, 2009, p. 258). Conflict is a natural phenomenon that happens in all organizations. It can also be described as an intentional action that is directed from one person to another in the organization to affect his/her capabilities and delay achieving the goals. Conflict usually happens because of the educational differences between individuals, and how they view their work and other's work. Therefore, it is natural to find some interactions between parties and individuals that lead to conflict, contradictions or discrepancy.

The organizational conflict was viewed as a behavioral and human phenomenon that appears according to the relationship among groups, families, clubs, or schools. So, the conflict arises because of the differences in points of views, in needs, in desires, in the role playing powers, in the search for power, and in the material and moral gain (Fraihat, 2009, p. 312).

The organizational conflict is one of different shapes of interaction. It can also be defined as a means of confusion and obstruction that destroy the work and decision making mechanism, and then a difficulty in choosing the appropriate alternative. Some scholars say that conflict, in a certain level, may play as a motive and a source of power that enhances job performance of both individuals and groups. But when it reaches a high level, it becomes so dangerous and will have much more negative effects such as grumbling, complaining, and criticism among employers and employees. There are two different views for organizational conflict, the classic, (traditional school), and the functional, (behavioral school). The first one views the conflict as something inevitable and undesirable, and must be eliminated or minimized through a well-chosen process of the individuals, training programs, clear job description, and periodical reorganization. These procedures usually decrease the undesirable conflicts. This school also asserts that it is very necessary to avoid conflicts in the organizations, Sharqawi (1992) says that this school looks at conflict as a kind of deficiency and failure in the organizational structure and this may affect negatively the efficiency and effectiveness of the organization.

As for the functional school, it views the conflict as a natural, organizational, and an inevitable phenomenon that accompanies the human relations in any organization. So, nobody can get rid of this phenomenon, and we have to get along with it, mange it, and get the utmost advantage of it. The behavioral school also looks at conflicts inside organizations as a necessary and a normal human phenomenon that leads to creativity and innovation, but sometimes it could be a tool for destruction and devastation.

Many people raise the question: Is the conflict negative all the time? To answer this question we can say that 
conflicts may develop the employee skills, activates their ideas, and increase the level of their creativity. This is so because the employee will look for new ways to accomplish his duties better than others, and then he becomes very qualified to choose the best alternative. This result can be achieved if the administrations listen carefully to their employees. Otherwise, the opposite will happen. Their creativity decays, job loyalty decreases, belonging to the organization weakens, job satisfaction appears like grumbling, complaining, criticism, lots of absence, lots of vacation demands, boring routine procedures, going to court to solve administrative problems, aggravating some simple administrative problems that may reach to the level of assaulting and beating.

Conflict happens in five stages (Abdelraheem, 2009, p. 223):

1). Hidden conflict stage: In which an appropriate organizational environment is existed to grow conflict, and the common goals and resources side by side with disparity between employers and employees in term of values, beliefs, and tendencies are also existed.

2). Visible conflict stage: In which some signs of conflict appear, and the parties of the conflict start managing it and identifying its effects on the goals and resources.

3). Tangible conflict stage: In which the employees and the parties start feeling the conflict on their own way, and everyone has the will and desire to solve it.

4). Apparent conflict stage: Some psychological reactions appear on this stage such as aggressiveness, withdrawal, continuing attempts, and searching for alternative solutions.

5). Conflict results stage and what comes after. Some decisions are made here to face, solve, and analyze the conflict in order not to happen again.

Sometimes it may happen for many people to hide all kinds of conflicts, worry, and tension for the purpose of performing their duties and then securing their jobs. In this case, the result is reflected on their behaviors, and some negative behaviors appear such as appeasing, relaxation, surrendering, submission, and isolation. One may ask what for does the conflict happen? The answer is to gain interests, or to have a full obsession, or to reach an absolute and effective power, or to be superior to others, or to loot resources, or to seize opportunities, or to invest the coming successes, or to exploit opportunities to increase gains, or to converse the victory into personal benefits, or to activate and maximize these benefits.

Organizational conflicts usually occur during work time. The organizational structure plays a vital role in bringing the appropriate environment for such conflicts, especially when the workers' roles are not specified, powers and authorities are not clear, and the job relationships are vague. This of course will lead to conflicts. The nature of work also causes conflicts when the worker neglects his duty and depends on others to do it. There are conflicts among groups which means to what extent the worker relies on others to accomplish his duties. Then, a state of tension, worry, and disappointment appeared. This means that relying on others and vague objectives increase the severity of conflict between the groups. Personal goals may contradict with each other which make some strong groups dominate other weak ones. The conflicts for roles may also cause conflicts inside the organization when the roles go against the needs, the values, and the trends of the workers. Sometimes the role could not be understood in the same way. In this case a conflict happens because the worker cannot satisfy the whole parties that he deals with. Overlapping roles may cause conflicts when somebody plays more than one role in the same organization. Competition on certain resources may lead to a conflict inside the organization, and then another conflict occurs among the groups when each one tries to gain more resources at the expense of others.

\section{Research Hypotheses}

Hypothesis 1: There is no effect of statistical indication at the moral level $(p \geq 0.05)$ for all the organizational frame on the organizational conflicts at the electric company of Irbid.

Hypothesis 1-1: There is an effect of statistical indication at the moral level $(p \geq 0.05)$ for the entire organizational frame on the organizational conflicts at the electric company of Irbid.

Hypothesis- 2

H-2 There is no effect of statistical indication at the moral level $(p \geq 0.05)$ for the nature and methods of the work of the organization on the organizational conflicts at the electric company of Irbid

H 2-1: The interdependence among employees at work does not lead to the organizational conflict.

H 2-2: The ambiguity of the goals and the means achieving them does not lead to the occurrence of the organizational conflict. 
H 2-3: Role conflict does not lead to the occurrence of the organizational conflict.

H 2-4: The overlap of different roles does not lead to the occurrence of the organizational conflict.

H 2-5: The competition of limited resources of the organization does not lead to the organizational conflict.

\subsection{Variables}

\section{The Independent Variable:}

- Interdependence at work;

- The ambiguity of the goals and the means achieving them;

- Role conflict;

- The overlapping roles conflict;

- The organizational structure of the organization.

The Dependent Variable: Organizational conflict.

\section{Research Methodology}

The researcher adopted the descriptive analytical approach to achieve the goals of the statistical research, and validate the hypothesis, which is based on two complementary types of studies: scientific research; a theoretical study, and field study. The theoretical study was adopted for the collection of the scientific material from theory and research through books, magazines, and previous studies that addressed the organizational conflict issue.

The scoping study and the field study field were adopted for the sample of the study which are represented by the workers in Irbid District Electricity Company in Jordan.

\subsection{Community of the Study}

The researcher marked all workers in Irbid District Electricity Company totaling (1000) employee as the population of the study. The study population included all levels of the upper and middle administration and executives.

\subsection{The Sample of the Study}

Taking researcher stratified random sample of all levels of the administrative staff in the company. The subjects of study were (150) of the company employees, heads and subordinates.

The percentage is $(15 \%)$ from the employees.

\subsection{Methods of Data Analysis}

The data were analyzed according to some statistical methods which are appropriate for the nature of the research including SSPS program. Through this program, the multiple regression method was used to measure the impact of a number of independent variables (forms and methods of the organizational conflict) on the dependent variable (job satisfaction), as well as the use of Pearson correlation which measures the strength and direction of the relationship between each variable of the independent variables, and with each variable of the dependent variables. The Bi method was used to determine the relationship of statistical significance between the different variables of the study. In addition to other methods, there are commensurate with the nature of the study, such as calculating the relative weights and repetitions.

\subsection{Research Terms}

The organizational Structure: A general framework that incorporates the goals, the administrative units, the authorities with the granted powers, the functional relationships, and lines of communication.

Style and the nature of the organization's work: The method used to accomplish specific business goals and to achieve the organization's goals.

Organizational conflict: It is a competitive position in which the parties of the conflict are aware of the discrepancy in accessing the future centers, and each party wants to get in the future centers which is contrary to the desire of the other party.

Interdependence in work: Any business that depends on the completion of another one or on other works.

Goals: The purpose for which the organization was found and what the organization seeks to achieve.

Role conflict: It occurs when a role contradicts with the needs of an individual, his values and trends. This role can be defined differently when we cannot understand what leads to a conflict inside the owner of the same role 
because of his inability to satisfy all the parties he deals with. This role also occurs when it contradicts with the needs of the individual and his values and trends.

Overlapping role conflict: It happens when one person performs more than one role in the organization.

Competition for resources: The competition on specific resources may cause conflicts within the organization, which leads to conflict within the groups due to the scarcity of resources. In such a case, each group makes the utmost effort to get the resources and benefits at the expense of other groups.

\section{Ststistical Analysis Methods of Data Collection}

In the process of gathering data, the researcher relied on primary and secondary data. The secondary sources include books, articles, literature, theses, laws, and regulations in order to clarify concepts related to the study, and to show the variables and their causes and effects. To establish and test the hypotheses, the researcher designed a Questionnaire, and formed the items according to the related theoretical frame of the study.

\subsection{The Size of the Study}

The study population consists of all the employees working in Irbid District Electricity Company totaling 1050 employees.

The sample of the study, For the purpose of choosing a representative sample, the researcher chooses a random sample of 150 persons, that is equal to $(15 \%)$ of the population, using Minitab Statistical program, where the researcher distributed questionnaire to them, and recovered 136 and 5 questionnaires were excluded because they were not valid for analysis. So the ratio of response was $90 \%$. The researcher used the 5-grade Likert scale to determine the approval of the study for each paragraph, and to convert them into a quantity data that can be statistically measured, then they were given the proportional weights shown in Table 1

Table 1. Scores of likert scale used in the study tool

\begin{tabular}{lll}
\hline The degree of scale & The degree of approval & Relative weight \\
\hline Strongly agree & 1 & $\% 20-0$ \\
Agree & 2 & $\% 40-21$ \\
I don't know & 3 & $\% 60-41$ \\
disagree & 4 & $\% 80-61$ \\
Strongly disagree & 5 & $\% 100-81$ \\
\hline
\end{tabular}

In the absence of the standard distribution that determines the importance of each paragraph, the arithmetic means were divided into three categories: (less than 2.5) means low level of importance, (2.5-less than 3.5) means medium level of importance, and (3.5-5) means high level of importance:

1-Honesty: The purpose of this test is to make sure that the statements contained in the study tool could lead to the collection of data accurately. To achieve this, the researcher consulted a group of specialists, and had their views and comments, which have a great impact on the revision and reworking some of the paragraphs that suffer from difficulty in understanding.

2-Believe content: intended to express the extent of the paragraphs of each area of study for the area to which it belongs. Attention has been focused on making sure that every area of study accurately represents a group of paragraphs, sincerity content was measured through a questionnaire to measure the relationship between each paragraph, and the area to which it belongs by using the Pearson correlation. Correlations have been adopted by more than $(30 \%)$, and the statistical significance of the task at the level of $(0.05 \geq \alpha)$.

\subsection{Tests of Measuring Tools}

\subsubsection{Validity of tools (Instrument Coefficient)}

Make sure that the tool that was used in this study actually measure what should be Measured. Study used tests of the sincerity tool used in many of the previous Studies (Sekaran, 2003), and Table 2 shows this relation. 
Table 2. Pearson correlation coefficient for measuring the sincerity content of the study tool

\begin{tabular}{lccc}
\hline A main paragraph correlation coefficient significance level Field & Paragraph & The correlation coefficient & The level of significance \\
\hline & 1 & $0.883(* *)$ & 0.000 \\
Interdependence at work & 2 & $0.762(* *)$ & 0.000 \\
& 3 & $0.825(* *)$ & 0.000 \\
Vagueness of the goals and the means to achieve them & 4 & $0.771(* *)$ & 0.000 \\
& 5 & $0.774(* *)$ & 0.000 \\
Role conflict & 6 & $0.705(* *)$ & 0.000 \\
& 7 & $0.502(* *)$ & 0.000 \\
Conflict overlapping role & 8 & $0.752(* *)$ & 0.000 \\
& 9 & $0.783(* *)$ & 0.000 \\
Completion for resources & 10 & $0.703(* *)$ & 0.000 \\
& 11 & $0.561(* *)$ & 0.000 \\
& 12 & $0.560(* *)$ & 0.000 \\
Organizational structure & 13 & $0.862(* *)$ & 0.000 \\
& 14 & $0.818(* *)$ & 0.000 \\
& 15 & $0.499(* *)$ & 0.000 \\
& 16 & $0.544(* *)$ & 0.000 \\
\hline
\end{tabular}

Note. Correlation coefficient statistically significant at the level $(0.01 \geq \alpha)$.

Table 2 shows that the previous results of Pearson correlation coefficient between the Paragraphs of each area of stud, and review the values of correlation coefficients and Levels of significance shows the presence of a statistically significant relationship at the Level of significance $(0.05 \geq \alpha)$ between the paragraphs of each area of the field of Study, which indicates the presence of sincerity builders of these paragraphs within its Own domain.

Second: The reliability coefficient (Reliability Coefficient): The researcher measured the stability of the tool after dividing it into six areas, using a measure of internal consistency, (Cronbach Alpha) for answers study sample were obtained, and is a value acceptable statistically for this measure $(60 \%)$ or more

Table 3. The internal consistency coefficient cronbach alpha fields of study and the tool as a whole

\begin{tabular}{lll}
\hline Field & Coefficient quantity & Cronbach \\
\hline Interdependence in work & 3 & 0.760 \\
Vagueness of the goals and the means necessary to achieve the goals & 3 & .612 \\
Role conflict & 3 & 0.648 \\
Conflict overlapping roles & 3 & 0.646 \\
Competition for resources & 3 & 0.687 \\
Organizational Structure & 6 & 0.792 \\
Tool tirelessly & 21 & .741 \\
\hline
\end{tabular}

Table 3 shows a Cronbach computed values, we find that it was high, and that the stability the paragraphs of the study tool as a whole was high (0.741), and indicates high stability of the questionnaire).

Statistical methods used in the analysis of data The researcher used a program of: (Statistical Package for Social Sciences (SPSS)) in the Analysis of the Data collected in this study. Study used several statistical Methods to Recruit. The data obtained to achieve the objectives of the study.

The following are the main methods that were used.

1) A Pearson correlation coefficient.

2) A cronbach alpha coefficient.

3) A descriptive statistical methods: frequency distribution, percentages, and the arithmetic. Mean, was used as 
the standard deviation.

4) A t-test for single sample (T-Test One Sample).

The characteristics of the study sample the study sample consisted of 136 employees, and Table 4 shows the distribution of the Sample according to personal variables.

Table 4. Distribution of the sample according to the variables of personal

\begin{tabular}{lllll}
\hline Variables & level & frequency & Percentage & Calculated percentage \\
\hline Gender & Male & 93 & 68.4 & 68.4 \\
& Female & 43 & 31.6 & 100.0 \\
& Total & 136 & $100 \%$ & \\
Experience & less than 5 years & 66 & 48.5 & 48.5 \\
& 5-less than 10 years & 48 & 35.5 & 83.8 \\
& 10-and more & 22 & 16.2 & 100.0 \\
\multirow{5}{*}{58 aualification } & Total & 136 & 100 & \\
& High school & 47 & 34.6 & 34.6 \\
& B A & 75 & 55.1 & 89.7 \\
& High studies & 14 & 10.3 & 100.0 \\
& Total & 136 & 100.0 & 100.0 \\
\hline
\end{tabular}

Table 4 shows the distribution of the sample according to gender. The results showed vast majority of the sample $(68.4 \%)$ were male, while the proportion of females is $(31.6 \%)$, as the previous table that there is a $(51.5 \%)$ of the members of the study sample increase their expertise for (5) years, and that this high level of expertise helps employees to answer the terms of resolution and make their answers more accurate, and that the rate of (48.5\%) had their years of experience (less than 5 years), while the percentage of the sample whose experiences come between (5 years to less than 10 years old) represent (35.3\%), and proportion (16.2\%) of a class that experience (over 10 years), as is also evident from the above table that the percentage of the study sample over the experience of five (5) Years were (51.5\%). By connecting this result with qualifications of the majority of the study sample holding BA (bachelors degree), we can say that the study sample had the ability to see organizational conflicts and their impact on the organization perfectly due to their experiences and qualifications.

The results indicated that the vast majority of the sample (51.1\%) is the holders of an undergraduate degree (BA), while the proportion of those with high school degree (34.6\%), and the lowest rate was for the campaign Graduate Certificate (10.3\%). Analysis and discussion of the results and hypothesis testing.

This chapter presents the most important results that have been reached. These results were presented within the two groups, the first group includes a descriptive presentation of the results of the study sample answers questions from the questionnaire, the results of the second group shows the test hypothesis.

First hypothesis:

1-1: There is no influence of the organizational structure on the organization.

1-2: There is influence of the organizational structure on the organization.

Table 5 shows the means, standard deviations, and the impact of the organizational structure on the organization, in a descending order of importance according to the average calculation. 
Table 5. Trends sample study about the impact of the organizational structure on the organization

\begin{tabular}{|c|c|c|c|c|c|c|}
\hline Rank & No & Paragraph & $\begin{array}{l}\mathrm{N}=136 \\
\text { The } \\
\text { arithmetic } \\
\text { mean }\end{array}$ & $\begin{array}{l}\text { Standard of } \\
\text { deviation }\end{array}$ & Percentage & $\begin{array}{l}\text { Degree of } \\
\text { importance }\end{array}$ \\
\hline 17 & 1 & $\begin{array}{l}\text { There is a job description in the organizational structure to } \\
\text { prevent conflicts }\end{array}$ & 4.18 & 1.05 & 83.53 & High \\
\hline 16 & 2 & $\begin{array}{l}\text { I depend on the rules and procedures when performing my } \\
\text { duties }\end{array}$ & 4.08 & 0.85 & 81.6 & High \\
\hline 18 & 3 & $\begin{array}{l}\text { There are many rules and standards preset control most of } \\
\text { aspects of my work }\end{array}$ & 3.99 & 0.83 & 79.71 & High \\
\hline 21 & 4 & $\begin{array}{l}\text { Information system provides the organization information } \\
\text { with a high degree of detail that required by the decision } \\
\text { maker in the executive administration }\end{array}$ & 3.96 & 1.03 & 79.26 & high \\
\hline 20 & 5 & There is a model written for each power relations & 3.93 & 1.03 & 78.68 & High \\
\hline 19 & 6 & $\begin{array}{l}\text { Any employee Penetrates the standards and rules faces a } \\
\text { clear punishment }\end{array}$ & 3.84 & 0.96 & 76.76 & High \\
\hline \multicolumn{3}{|c|}{ General trend } & 4.00 & 0.67 & 79.93 & High \\
\hline
\end{tabular}

Table 5 shows that the views of a sample study about the impact of the organizational structure of the organization, came of high importance to all paragraphs, and the results indicated that the most influential paragraph was \# 17 which states that there is a job description in the organizational structure to prevent conflicts with a mean (4.18) by (83.53\%), which is located within a high degree of influence, and the standard deviation (1.05), due to the fact that the organizational structure is not clear to all employees in terms of the levels of the administration and the relationship among workers.

Paragraph (16), states that "I depend on the rules and procedures when performing my duties", comes in the second rank with a mean (4.08) by (81.62\%), and a standard deviation (0.85). This may indicate that the formal communication between workers is dominant, and that the organization is driven by rules and regulations.

In the third place of influence came paragraph (18), which states that "There are many rules and standards that control most of aspects of my work" with Average (3.99) and percentage (79.71\%) and located within a high degree influence, and a standard deviation (0.83), and this is due to the fact that strict adherence to the rules and regulations is the basis of the work.

The less influential paragraphs from the workers' point of view of the company in terms of the effect of the organizational structure on the organization was paragraph (19). It states that "Any employee who violates the standards and the rules will face a clear punishment" with a mean (3.84) by $(76.76 \%)$. It is located within a high degree of emotion, and a standard Deviation (0.96), and this indicates that there are punishments for those who are not committed to rules of the company. And, while that paragraph (20), which states that "There is a Written form for all Authority relations", and with average (3.93) percentage (78.68\%), and a standard deviation (1.03).

In general, the results of Table 5 indicates that the ratio of the effect of the organizational structure on the organization is $80 \%$, with a high domain. This means that the workers must commit themselves with the organizational structure and the rules of the organization. The standard deviation for all the questions was low (0.67). This shows similar responses and no distraction among the workers' points of view about the study variables.

The Result of the First Hypothesis Test: To test the first hypothesis, the researcher used (t-test) for the single sample (One Sample ( T-test). It is clear that the results in Table (5) that the value Of (t) was statistically significant at the level (1\%) and so, the first hypothesis (1-1) will be rejected, and there is a high influence of the organizational structure on the organization.

Table 6. T-Test of the single sample, the effect of the organizational structure on the organization

\begin{tabular}{lllllll}
\hline Field & $\begin{array}{l}\text { The arithmetic } \\
\text { mean }\end{array}$ & $\begin{array}{l}\text { Standard } \\
\text { deviation }\end{array}$ & of & $\begin{array}{l}\mathrm{T} \text { calculated } \\
\text { value }\end{array}$ & $\begin{array}{l}\text { Degree } \\
\text { freedom }\end{array}$ & $\begin{array}{l}\text { Level } \\
\text { significance }\end{array}$ \\
\hline $\begin{array}{l}\text { The impact of the organization structure on } \\
\text { the organization }\end{array}$ & 4.000 & 0.67 & 21.22 & 135 & 000 & of \\
\hline
\end{tabular}


Table 6 shows the results of the previous (t) test of the first hypothesis (1-1) about the influence of the organizational structure on the organization. The results indicate that workers at the electricity company in Irbid district realize that there is an influence of the organizational structure on the organization, with a mean total (4.00) and ratio $(80 \%)$, with statistically significant at the level $(1 \%)$. This indicates the presence of the impact of the organizational structure on the organization with a high degree, so, the first hypothesis (1-1) is rejected. And we accepted the hypothesis (1-2) There is an impact of the organizational structure on the organizational conflict with a high Degree.

Hypothesis 2-1: There is no impact of the adoption of the mutual work in the organization.

Table 7. The impact of the adoption of the mutual work in the organization

\begin{tabular}{|c|c|c|c|c|c|c|c|}
\hline \multirow[t]{2}{*}{ Rank } & \multirow[t]{2}{*}{ No } & \multirow[t]{2}{*}{ Paragraph } & \multicolumn{4}{|l|}{$\mathrm{N}=136$} & \multirow{2}{*}{$\begin{array}{l}\text { Degree } \\
\text { importance }\end{array}$} \\
\hline & & & $\begin{array}{l}\text { The arithmetic } \\
\text { mean }\end{array}$ & $\begin{array}{l}\text { Standard } \\
\text { deviation }\end{array}$ & of & Percentage & \\
\hline 1 & 1 & $\begin{array}{l}\text { I have a lot of stress and anxiety because of the late } \\
\text { arrival of practical tools }\end{array}$ & 3.89 & 0.66 & & 77.79 & High \\
\hline 2 & 2 & $\begin{array}{l}\text { The delay in completing the work group because of } \\
\text { its delay in performance }\end{array}$ & 3.60 & 0.98 & & 71.91 & High \\
\hline 3 & 3 & $\begin{array}{l}\text { Other working groups cooperate with me causes the } \\
\text { stress, anxiety and headache }\end{array}$ & 3.09 & 0.82 & & 3.09 & Medium \\
\hline \multicolumn{3}{|c|}{ Genral trends } & 3.52 & 0.98 & & 70.49 & High \\
\hline
\end{tabular}

Notes from Table 7, the views of workers in the electricity company in the province Irbid are of high importance to all the paragraphs related to the interdependence in the work, with the exception of paragraph (3) medium were important. The results indicated that more paragraphs of interdependence in action impact on the organization was: "I have a lot of stress and anxiety because of the late arrival of tools practical," and that a mean (3.89) by (77.79\%), which is located within the high-grade, standard deviation (0.66), and perhaps this shows that some units working tools and means are good and some of the other work tools and methods are not good or unavailable.

According to the importance of the second "delayed the working group in completing its cause delay in performance" with a mean total (3.60) by (71.91\%), a high percentage, and a standard deviation (0.98), and this may indicate that the lack of means and tools hinders my game to work than delay the work required done.

A result of T- test hypothesis 2-1: To test hypothesis 2-1, the researcher has used the T-test of the sample (One Sample T-Test). It is clear from the test and the results in Table 6 that the value of (t-test) were DAT statistically significant at the level (1\%) and hypothesis $2-1$ will be rejected. And we accept the indicates that There is an effect of the adoption of the mutual work in the organization.

Table 8. T-test of the single sample in the field of the effect of work interdependence on the Organization

\begin{tabular}{|c|c|c|c|c|c|c|}
\hline Field & The arithmetic mean & $\begin{array}{l}\text { Standard } \\
\text { deviation }\end{array}$ & of & T calculated value & Degree of freedom & $\begin{array}{l}\text { Level of } \\
\text { significance }\end{array}$ \\
\hline $\begin{array}{l}\text { Interdependence at } \\
\text { work }\end{array}$ & 3.52 & 0.98 & & 5.68 & 135 & 000 \\
\hline
\end{tabular}

Field arithmetic average of the standard deviation value $(t)$ degree of freedom is calculated level of statistical significances Interdependence at work 3.520 .985 .681350 .00

Hypothesis 2-2: There is no influence of the ambiguity of the goals and the means to achieve them on the organization. 
Table 9. The impact of the sample study trends about the ambiguity of the goals and the necessary means on the organization

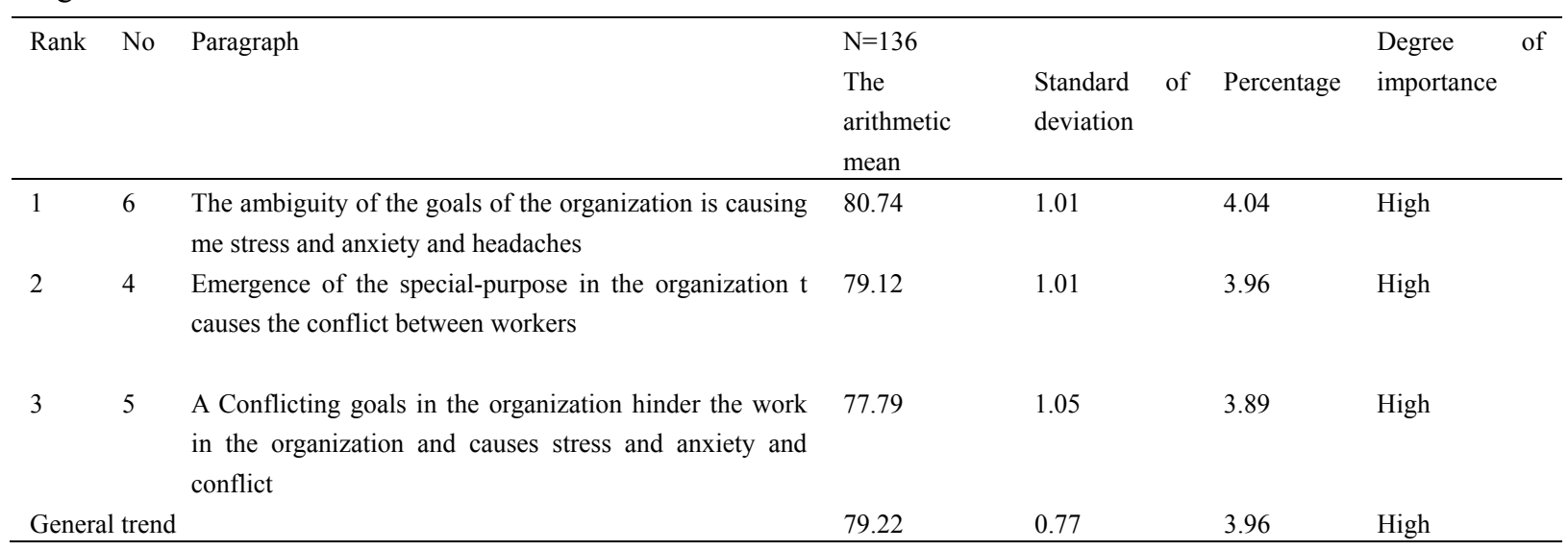

Table 9 shows that the views of workers in electricity company in the province of Irbid were of high importance to all items related to the impact of the ambiguity of the goals and the means necessary to achieve the goals of the organization. The results indicated that more paragraphs of the ambiguity of the goals and the means to achieve an impact on the organization was "the ambiguity of the goals of the organization causes stress, anxiety and conflict" with a mean $(4.04)=(80.74 \%)$, which is located within the high-grade domain with standard deviation (1.01). This explain why the workers could not get the information and knowledge related to their jobs.

According to the importance of the second "emergence of personal-purpose in the Organization causes conflict among employees" with a mean total (3.96) by (79.12\%), a high Percentage, and a standard deviation (1.01), suggesting that the workers are looking for their Own interests because they lack interest in the administration, and their attitudes, Making their career loyalty and belonging to the organization very weak.

As for the Least paragraphs impact on the organization, it was paragraph (3), which States that "the conflicting goals of the organization in the organization hinder the work and cause stress and anxiety and conflict" with a mean (3.89) by (77.79\%), this is located within the degree of emotion high, and the standard deviation (1.05), which means that there are conflicting purposes within the organization, and that there is resistance from influential modernization and change.

In general, the results indicate that the ratio of the average effect of the ambiguity of the goals and the means necessary to achieve the organization goals was (3.96) by (79.22\%), which is located within the high-grade, which means that the vagueness of the goals and the means necessary to achieve it, affects the organization by the influence $(79.22 \%)$, and indicates to the lack of information and lack of familiarity with the goals of the organization's main and subsidiary, and non-stick by those in charge of the administration clearly, and not knowing it led to the emergence of purpose workers, and that the standard deviation of all the questions was low (0.77). This refers to the convergence answers of the sample study, and the absence of a large dispersion among them.

As a result of hypothesis 2-2: To test hypothesis (2-2) has been using the (T-test) of the sample single (One Sample (T-Test), it is clear from the test results in Table 9 that the value of (t-test) were DAT statistically significant at the level (1\%) and it will reject hypothesis (2-2), refers to the effect, and we accepted that: There is an ambiguity of the goals and the means necessary to achieve the organizational goals with a high degree.

Table 10. Test ( $\mathrm{t}$ ) of the single sample to field of the impact of the vagueness of the goals and the means to achieve them

\begin{tabular}{|c|c|c|c|c|c|}
\hline Field & The arithmetic mean & $\begin{array}{ll}\text { Standard } & \text { of } \\
\text { deviation } & \\
\end{array}$ & T calculated value & Degree of freedom & $\begin{array}{ll}\text { Level } & \text { of } \\
\text { significance } & \\
\end{array}$ \\
\hline The & 3.96 & 0.77 & 14.59 & 135 & 000 \\
\hline $\begin{array}{l}\text { Vagueness of the } \\
\text { goals and the means } \\
\text { to achieve them }\end{array}$ & & & & & \\
\hline
\end{tabular}

H 2-3: There is no impact of conflict role on the of the organization. Table 10 shows that the views of workers in 
Irbid District Electricity Company about the impact of conflict role on the organization was a medium effect, with the exception of paragraph (7) was a high-impact, where the results indicated that the important paragraphs impact the organization was "The works that I do are compatible with my trends and my social values" with a mean (3.94) by (78.82\%), and a standard deviation (1.09), and it could indicate that the business is distributed in proportion to the capacity of workers and their desires.

While "my duties in the organization is not clearly defined," came second; influence in the rank on the organization with average (3.18) by (63.68\%), and a standard deviation $(0.87)$, mean that the tasks are mostly well-defined.

Table 11. Trends of the sample study about the impact of conflict role on the organization

\begin{tabular}{|c|c|c|c|c|c|c|}
\hline \multirow[t]{2}{*}{ Rank } & \multirow[t]{2}{*}{ No } & \multirow[t]{2}{*}{ Paragraph } & \multicolumn{3}{|l|}{$\mathrm{N}=136$} & \multirow{2}{*}{$\begin{array}{ll}\text { Degree of } \\
\text { importance }\end{array}$} \\
\hline & & & $\begin{array}{l}\text { The arithmetic } \\
\text { mean }\end{array}$ & $\begin{array}{l}\text { Standard of } \\
\text { deviation }\end{array}$ & Percentage & \\
\hline 1 & 7 & $\begin{array}{l}\text { The work that I do are consistent with my social } \\
\text { values and My social trends }\end{array}$ & 3.94 & 1.09 & 78.82 & High \\
\hline 2 & 9 & my duties in the organization is clearly defined & 3.18 & 0.87 & 63.68 & Medium \\
\hline 3 & 8 & $\begin{array}{l}\text { The work I do is contradict with my religious values } \\
\text { causing me stress and psychological conflict }\end{array}$ & 3.00 & 0.90 & 60.00 & Medium \\
\hline \multicolumn{2}{|c|}{ General trend } & & 3.38 & 0.93 & 67.50 & Medium \\
\hline
\end{tabular}

The less influential paragraphs from the viewpoint of workers in Irbid Electricity Company was that the employee "is acting contrary to the religious values, causing them stress and psychological conflict" average (3.00) by $(60.00 \%)$, which fall within the class medium influence and standard deviation (0.90), and explains that works are completed in line with the wishes of the workers. We note from the above table that the ratio average of the effect of role conflict on the organization was (3.38) by (67.50\%), and it falls within the middle-grade, while the standard deviation was low (0.93), and this refers to the convergence answers of the study sample, and the absence of scattering them.

A result of hypothesis 2-3 test: To test hypothesis 2-3 that has used (t- test) in the sample single (One Sample T-Test), it is clear from the results of the test in Table (11) that the value of (t) with statistically significant at the level $(1 \%)$ and the third hypothesis will be rejected. This indicates that the conflict role affects the organization with a high degree.

Table 12. The impact of the conflict role on the organization

\begin{tabular}{|c|c|c|c|c|c|c|}
\hline Field & The arithmetic mean & $\begin{array}{l}\text { Standard } \\
\text { deviation }\end{array}$ & of & $\mathrm{T}$ calculated value & Degree of freedom & $\begin{array}{l}\text { Level of } \\
\text { significance }\end{array}$ \\
\hline $\begin{array}{l}\text { The impact of the } \\
\text { conflict role on the } \\
\text { organization }\end{array}$ & 3.38 & 0.93 & & 4.72 & 135 & 0.000 \\
\hline
\end{tabular}

Hypothesis 2-4: There is no effect of the overlapping conflict role on the organization. Table 13 shows that the views of workers of Irbid District Electricity Company about the impact of overlapping conflicts role on the organization was high, with the exception of paragraph (11) which was medium, where the results indicated that the most paragraph impact on the organization was "I prefer to work specific and clear duties" with average (4.17) by $(83.38 \%)$, and a standard deviation (0.68). It could also indicate that the administration take the wishes of the workers in its account.

While the effect of "I do a different implementation tasks in the organization" came the second in the influence rank in the organization with average (3.68) by (73.53\%), and a standard deviation (0.59), this means that the employee may ask to do duties in addition to his main duties. 
Table 13. The sample study trends about the impact of the overlapping conflict roles on the organization

\begin{tabular}{|c|c|c|c|c|c|c|c|}
\hline \multirow[t]{2}{*}{ Rank } & \multirow[t]{2}{*}{ No } & \multirow[t]{2}{*}{ Paragraph } & \multicolumn{4}{|l|}{$\mathrm{N}=136$} & \multirow{2}{*}{$\begin{array}{l}\text { Degree } \\
\text { importance }\end{array}$} \\
\hline & & & $\begin{array}{l}\text { The arithmetic } \\
\text { mean }\end{array}$ & $\begin{array}{l}\text { Standard } \\
\text { deviation }\end{array}$ & of & Percentage & \\
\hline 12 & 1 & I prefer to work a specific and clear duties & 4.17 & 0.6883 & & .38 & High \\
\hline 10 & 2 & $\begin{array}{l}\text { I do different implementation tasks in the } \\
\text { organization }\end{array}$ & 3.68 & 0.59 & & 73.53 & High \\
\hline 11 & 3 & $\begin{array}{l}\text { Multitasking makes me unable to satisfy all } \\
\text { parties in the organization }\end{array}$ & 3.43 & 0.80 & & 68.53 & Medium \\
\hline \multicolumn{3}{|c|}{ General trend } & 3.76 & 0.73 & & 75.15 & High \\
\hline
\end{tabular}

The less influential paragraph from the standpoint of workers of Irbid District Electricity Company was "multitasks makes me unable to satisfy all parties in the organization," with average (3.43) by (68.53\%), which is located within the class medium influence and standard deviation (0.80). It might be that every employee has more than one supervisor at work. We note that the ratio of the average effect of the impact of the overlapping conflict roles on the organization was (3.76) by $(75.15 \%)$, and fall within the class of high impact. This means that the multiplicity of supervisors hinder the work and causes tension, and the standard deviation was low (0.73). This refers to the convergence answers of the study sample, and the absence of scattering them.

The result of hypothesis (2-4) test: To test hypothesis( 2-4) which used test (t) of the single sample (One Sample $\mathrm{T}-$ Test), it is clear from the results of the test in Table (12) that the value of ( $\mathrm{t})$ with statistically significant at the level $(1 \%)$, the hypothesis will be rejected, and indicates that there is a high degree of effect of the overlapping conflict on the Organization.

Table 14. The effect of overlapping role on the organization

\begin{tabular}{lllllll}
\hline Field & $\begin{array}{l}\text { The arithmetic } \\
\text { mean }\end{array}$ & $\begin{array}{l}\text { Standard } \\
\text { deviation }\end{array}$ & of & $\begin{array}{l}\text { T calculated } \\
\text { value }\end{array}$ & $\begin{array}{l}\text { Degree } \\
\text { freedom }\end{array}$ & $\begin{array}{l}\text { of } \\
\text { significance }\end{array}$ \\
\hline $\begin{array}{l}\text { The effect of the overlapping role on the } \\
\text { organization }\end{array}$ & 3.76 & 0.73 & 12.10 & 135 & 000 \\
\hline
\end{tabular}

Hypothesis 2-5: There is no impact of the competition for resources on the organization.

Table 15. Trends of the sample study about the competition effect on the organization

\begin{tabular}{|c|c|c|c|c|c|c|}
\hline \multirow[t]{2}{*}{ Rank } & \multirow[t]{2}{*}{ No } & \multirow[t]{2}{*}{ Paragraph } & \multicolumn{3}{|l|}{$\mathrm{N}=136$} & \multirow{2}{*}{$\begin{array}{l}\text { Degree of } \\
\text { importance }\end{array}$} \\
\hline & & & $\begin{array}{l}\text { The arithmetic } \\
\text { mean }\end{array}$ & $\begin{array}{l}\text { Standard } \\
\text { deviation }\end{array}$ & Percentage & \\
\hline 15 & 1 & $\begin{array}{l}\text { The resources distributed to departments in the } \\
\text { organization according to the degree of the influence of } \\
\text { each department }\end{array}$ & 3.98 & 0.97 & 79.56 & high \\
\hline 13 & 2 & $\begin{array}{l}\text { The Organization defines specific resources for each } \\
\text { district equally }\end{array}$ & 3.63 & 0.84 & 72.50 & high \\
\hline 14 & 3 & $\begin{array}{l}\text { If I got not specific resources to accomplish my duties the } \\
\text { conflict raises within the organization }\end{array}$ & 3.58 & 1.20 & 71.62 & high \\
\hline \multicolumn{3}{|c|}{ General trend } & 3.73 & 0.93 & 74.56 & high \\
\hline
\end{tabular}

Table 15 shows that the averages, standard deviations, and the impact of competition on the resources are organized in descending order of importance according to the average calculation. The table shows that the views of workers in Irbid District Electricity Company sample study, are of high importance to all the paragraphs related to the impact of the competition for resources in the organization. The results also indicated that the most influential paragraphs was paragraph (15) which states: "The resources are distributed to departments of the organization according to the degree of the influence of each department" with a mean (3.98) by (79.56\%), and a 
standard deviation (0.97). This means that the workers in this company are facing the problem of lack of access to resources between sections.

According to the needs of each department. Also, paragraph (13), which states "The organization distributes specific resources for each district equally" were ranked the second with a mean (3.63) by (72.5\%), which comes in the high degree of influence and standard deviation (0.84). Here the respondents say that the means and tools may not be available to all sections according to their needs to accomplish their work.

The result of the test of hypothesis (2-5): To test hypothesis (2-5), (t-test) has been used for the single sample (One Sample (T-Test). The results in Table (15 shows that the value of $(\mathrm{t})$ is of statistically significant at the level (1\%) and the fifth hypothesis will be rejected, indicating that the effect of the resources on the organization is very high.

Table 16. T-test of the single sample to find the effect of resource competition on the organization

\begin{tabular}{|c|c|c|c|c|c|c|}
\hline Field & The arithmetic mean & $\begin{array}{l}\text { Standard } \\
\text { deviation }\end{array}$ & of & T calculated value & Degree of freedom & $\begin{array}{l}\text { Level of } \\
\text { significance }\end{array}$ \\
\hline $\begin{array}{l}\text { The impact of } \\
\text { competition on the } \\
\text { organization }\end{array}$ & 3.73 & 0.93 & & 9.15 & 135 & 000 \\
\hline
\end{tabular}

\section{Findings and Recommendations}

\subsection{Results of the Study}

1) The organizational hierarchy of the institution considered a powerful element for it. Since the organization lives in an environment surrounded by variables. So, it must deal with them and response successfully. If the organization is flexible, it will be able to meet responses and challenges and keep up with development and growth. The study found that the organizational hierarchy of Irbid electricity company LTD. It was based since it was established, and it was starting to be developed by size and range in work region. The company should take into account its organizational hierarchy form one time to another. Late in conducting the necessary modifications may be reason for regulatory conflicts.

2) The means, tools, and equipment are considered important for achieving the duties. They are power for the organization, ensure the continuation of its business, achieve satisfaction of the employees and cooperation, and reduce arguments among them. The study found that there is a complaint with some employees in the company for lack in some necessary tools for completing the work which will delay it and cause stress and anxiety when working, which may cause regulatory conflicts.

3) Sometimes, an employee plays more than one role. This causes nervous and anxiety because of not to determining the tasks and the main duties for very employee. The study found that employees in Irbid Electricity Company suffering from lack of identification of key business and clearly specified for each of them. This causes anxiety and nervous for employees and their sense of dissatisfaction.

4) Transforming information among employees considered the base of cooperation on different managerial levels. The organization will be successful. If transformation is transformed among employees, it will cause negative relations effect on achieving business. The study found that useful information in completing the business does not transfer among employees causing mistrust, suspicion and regulatory conflicts among them.

5) The employees adopt particular missions for being at the organization. These missions maybe contradicted with each other. To achieve the missions and objectives, we should reduce using the contradictive methods because they cause regulatory conflicts. The study found that there are private missions for who work in the company and regulatory conflicts happened because every employee team seeks to use unlegislative means and tools to achieve the objectives even exceeding the objectives of the organization and others.

6) Business are achieves in the organization by depending on one another. They need tools and means to be achieved. The lack of these tools and means provided regulatory conflicts. The study found that a lot of business delayed to be completed and achieved due to lack of tools.

\subsection{Recommendations}

The study has recommended in following suggestions:

1) The company has to conduct a review for organizational hierarchy to deal with the necessary modifications in order to response for the environmental variables and rapid development in its business, expanding in its 
branches, and reduce the regulatory conflicts. It is the one and only company which provides the service of electricity for the dwellers in north of Jordan.

2) Since business has done through specific tools and instruments, the company must provide all employees the means and tools not to delay the work. It should be noted that units of business depend on other work units.

3) Since organizations seek to achieve privacy in the field of work, employee must do a main work where he is responsible on. The study recommends that everyone determines his main work to achieve the work directly.

4) Because of objectives opposing by the employees of the company, there will be difficulties an cause regulatory conflicts.

Due to the above mentioned recommendations, the study also recommends in the necessity to configure between the objectives of the organization and objectives of employees in order not to have regulatory conflicts.

There are a lot of rich who look for achieving their objectives and impede processing and development. So, they must be monitored and controlled.

\section{References}

Aassi, S. A. S. (1995). The impact of role conflict and ambiguity on job satisfaction for sellers in retail shops on Omar Effendi vendor company. Magazine for commercial research, the Faculty of Commerce, University of Zigzag.

Abdul, R., \& Atef, J. (2009). Organizational Behavior. Alexandria, Egypt: University House Publishing.

Abo, S., \& Nader, A. (2010). Organization climate and its relation with the personal variables personal and functional variables. Journal of Economics and Management, 2(19).

Ahmed, B. H. (1994). Reading In organization behavior.

Al, O., \& Mahmud, S. (2005). Organizational behavior in business organization Dar Wail for Publication and distribution (3rd ed.).

Al, Q., Salem, S., \& Joseph, S. A. (2001). The reasons of organizational conflicts in Central agencies in Saudi Arabia, King Saud University. Journal of Administrative Sciences.

Al, T., \& Hani, A. (1986). Educational of administration and organizational behavior (1st ed.).

Alfrehat, K. K., Mousy, A. L., \& Inaam. (2009). The university library, enriching for publication and distribution. Jordan

Burgdh, H. O. (2005). Organizational Conflict Management. Journal of Economic Sciences and Science of Marketing.

Geldeh, S. (2009). Organizational Behavior and modern theories management. Dar Osama for publishing \& distribution, Amman, Jordan.

Hamad, M. H. O. (2002). Evaluation of management techniques of organizational conflicts between managers of middle-management companies of natural gas distribution and trends of development. Sadat Academy for Management Sciences.

Hassan, M. A. G., \& Sabri, M. N. (1999). Analysis of managers trends towards the determinants of organizational conflict, on the application of the regulatory service sectors in east Egypt. Journal of Business Research.

Judah, I. S., \& Yafei, R. S. (2007). The relationship between leadership style career commitment and role conflict ambiguity, and some demographic variables in public sector companies in Egypt Arab Republic. Arab Journal of Administrative Sciences, 14(3).

Nada, F. S. (1991). The impact of environmental variables, organizational of behavioral variables of performance of the efficiency of hospitals (a comparative study with the application on public hospitals and General hospitals Authority for Health Insurance) Ph.D. Thesis, University of Cairo, Faculty of Commerce, 1991.

\section{Copyrights}

Copyright for this article is retained by the author(s), with first publication rights granted to the journal.

This is an open-access article distributed under the terms and conditions of the Creative Commons Attribution license (http://creativecommons.org/licenses/by/3.0/). 